\title{
Dune development and aeolian transport along the Holland coast
}

\author{
Sierd de Vries ${ }^{1,2}$, Howard Southgate ${ }^{1}$, Wim Kanning ${ }^{1}$ and Roshanka Ranasinghe ${ }^{1,3}$. \\ ${ }^{1}$ Section of Hydraulic Engineering, Delft University of Technology, Delft, 2628 CN, The Netherlands \\ ${ }^{2}$ Building with Nature, EcoShape, Burgraadt Building, Dordrecht, 3311 JG, The Netherlands \\ ${ }^{3}$ Department of Water Engineering, UNESCO-IHE, PO Box 3015, 2601 DA Delft, The Netherlands \\ Sierd.deVries@tudelft.nl; W.Kanning@tudelft.nl; H.N.Southgate@tudelft.nl; R.Ranasinghe@unesco-ihe.org
}

\begin{abstract}
This paper presents an analysis of annual to decadal dune behavior along the Holland Coast. In the database of the JAarlijkse KUStmeting (JARKUS) a very large collection of yearly measured profiles is available for analysis. These measured profiles are used to extract a selection of parameters relevant to the development of dunes which are inter-comparable in time and between profiles. Special attention is given to dune volume changes and parameters which could influence aeolian transport such as the beach slope and annual wind conditions.

It is found that the beach slope is significantly correlated with dune volume changes on an annual timescale. No temporal lag between the two parameters is found. Additionally, annual wind conditions are found not to correlate with dune volume changes; windy years do not show different dune volume changes than relatively quiet years.

The results of this analysis provides new insight on processes governing aeolian transport and how to model aeolian transport and dune development. Extending the analysis to more areas along the Dutch coast could give more information on specific processes regarding dune behavior.
\end{abstract}

\section{INTRODUCTION}

The dune area along the Dutch coast is subject to natural variability as well as variability induced by anthropogenic activity (Bochev-van der Burgh et al. 2011). Natural variability is a result of aeolian and marine processes. Whereas nourishments change the dune morphology directly or indirectly via the influence on transport processes.

Annual dune volume changes are considered as a measureable parameter representing dune development. Figure 1 gives an overview of processes influencing the dune volume change. In this paper we focus on aeolian transport and therefore dune volume changes in relation to wind forcing and beach slope (profile shape in Figure 1) in particular.

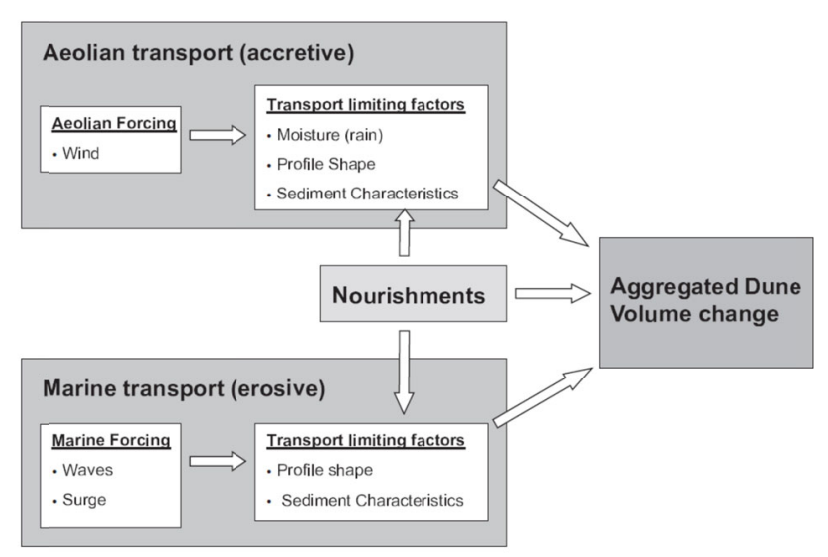

Figure 6. Conceptual representation of dune volume change aggregated over time. Accretive periods are alternated with erosive periods. Nourishments directly affects the dune volume changes as well as transport limiting factors

\section{DATA AND METHOD}

Two datasets are used for this study. (1) The Holland coast section of the Dutch JAarlijkse KUStmenting (JARKUS) see Figure 2. (2) Wind measurements gathered at a weather station at IJmuiden by the Royal Dutch Meteorological Institute (KNMI). Both datasets are elaborated upon below.

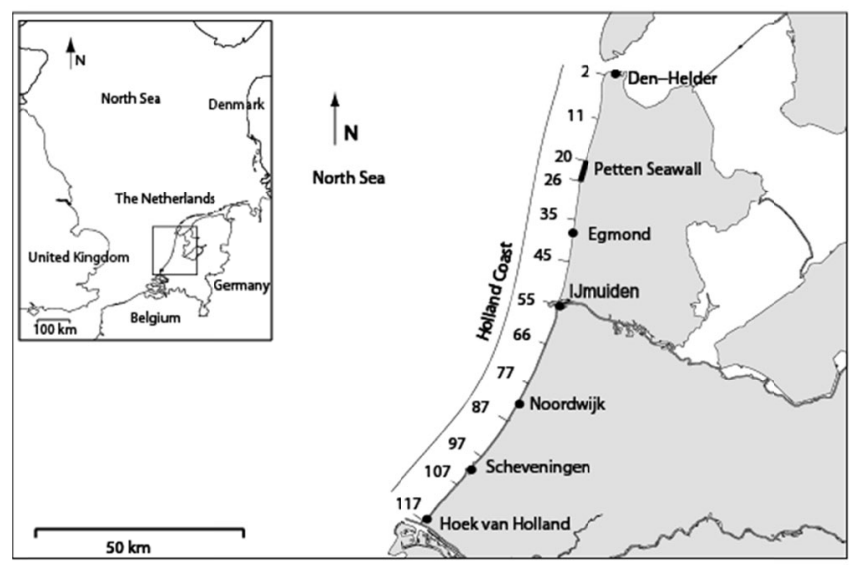

Figure 7. Overview of the Holland coast. Numbers indicate alongshore kilometers with respect to the most northern point of the Holland coast. The Pettien sea wall and the harbors of IJmuiden and Scheveningen are indicated 

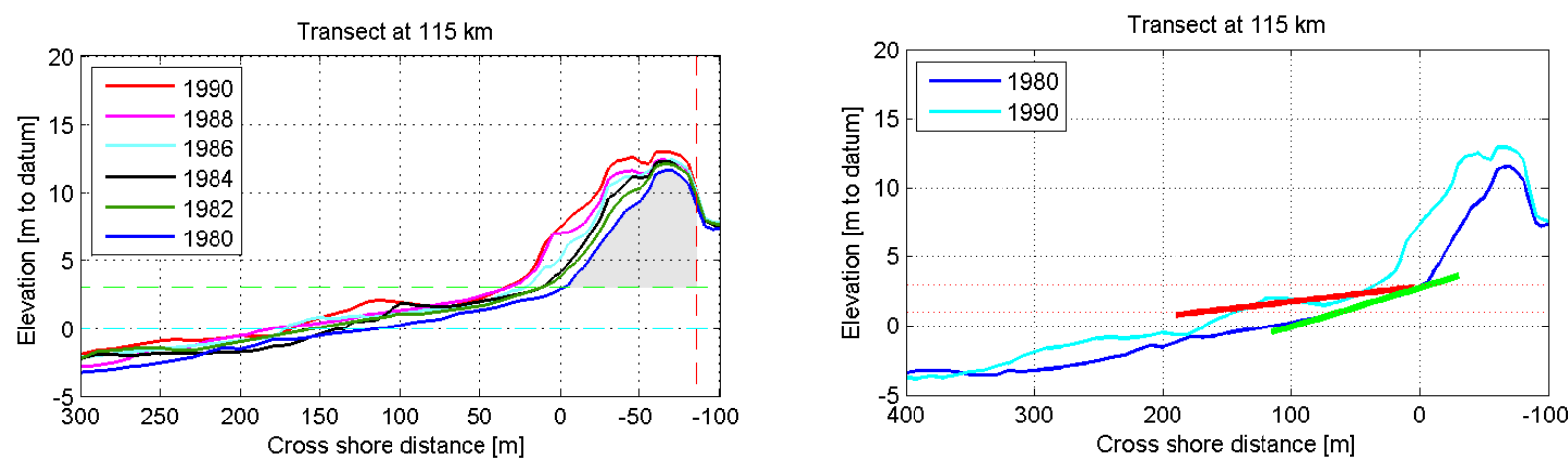

Figure 3.- Left panel shows the definition of the dune volume where the colored lines show profile measurements at an arbitrary transect location. The vertical red dashed line indicates the stable point boundary the green dashed line the dunefoot level and the gray area the dune volume derived for 1980 - Right panel shows the derived beach slope for an arbitrary transect location and two arbitrary years.
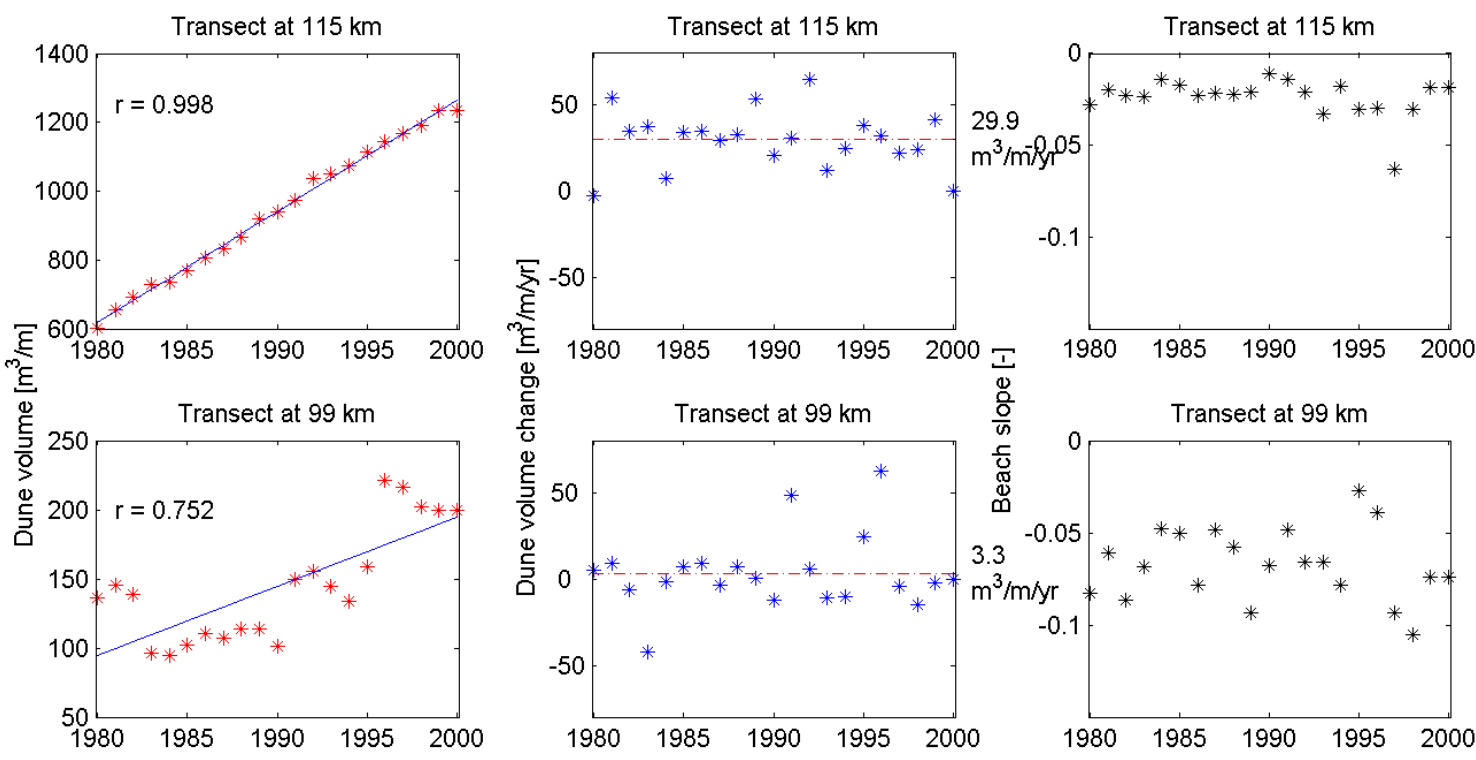

Figure 4. Left panel shows dune volume development over time at two different transect locations. Middle panels shows the associated dune volume changes over time together with the mean dune volume changes indicated. Right panel shows the development of beach slope over time.

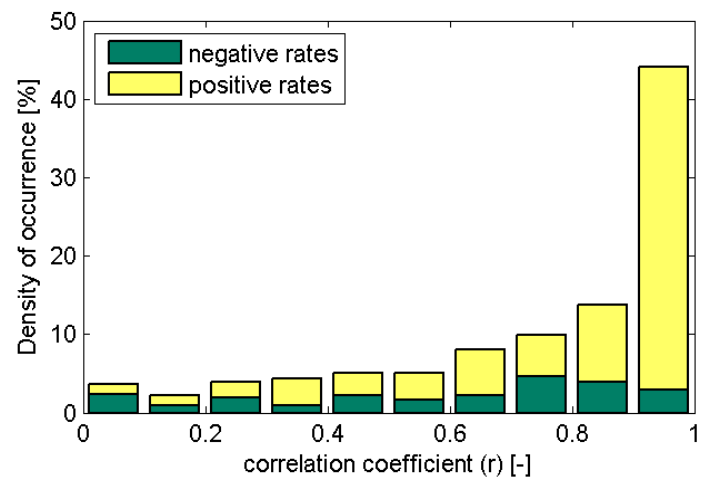

Figure 5. Density of occurrence of correlation coefficients fitting a linear trend on dune volume development at every transect location. 


\section{JARKUS - data}

The Holland coast section of the JARKUS data consists of 593 annual profiles covering $117 \mathrm{~km}$ with $250 \mathrm{~m}$ spacing. The time window considered is $1980-2000$. The annual profiles are used to derive Dune Volumes (DV) and beach slopes.

\section{Dune Volume (DV)}

In order to derive Dune Volumes using the measured profiles from the JARKUS dataset generic boundaries are needed. In this paper we choose the dunefoot level at $+3 \mathrm{~m}$ NAP as a lower limit boundary of the dune volume. For the second boundary a landward static point is derived using a timeseries. The static point is located where the vertical variance of the bed level elevation is lower than a certain limit. Figure 3 (left panel) shows the dune volume over consecutive years together with the defined boundaries. Boundaries and dune volumes are derived for every transect location. Therefore references vary and absolute values of dune volumes are dependent on these references. As a result the absolute values of dune volumes are not of particular interest because they are not intercomparable between transect locations. However the year to year changes in dune volume are intercomparable. Figure 4 shows the development of the dune volume and dune volume changes for two arbitrary profiles.

It is shown that at particular transect locations the dune volume development is very well represented by a linear trend in time. Although the development of dune volume is not well represented by a linear trend at all transect locations (also shown in Figure 4), a large percentage of transect locations is. Figure 5 shows that around $44 \%$ of all measured transect locations show correlations coefficients of 0.9 and higher.

\section{Beach Slope}

In this paper the beach is defined as the part of the transect bordered by the dune (at +3 m NAP) and the Mean Water Level (MWL). The beach slope is defined as the gradient of the best linear fit using a least square method. Figure 3 (right panel) shows the beach slope for an arbitrary transect at two moments in time. Beach slopes are generally between 0 and -0.1 and show some variability in time, see Figure 4.

\section{Wind conditions - Resultant Drift Potential}

Following the method of Fryberger 1979, the Drift Potential (DP $[\mathrm{m} 3 / \mathrm{m} / \mathrm{s}])$ is the transport potential of measured wind conditions. Equation 1 is used to calculate wind speed $(u)$ to potential transport $\left(q_{r}\right)$ where $u_{t 0}$ is the transport velocity for the initiation of aeolian transport.

$$
q_{r} \propto\left(u^{2}-u_{t 0}^{2}\right) u
$$

Equation 1 is a simplified version of the sediment transport formulation by Hardisy and Whinehouse (1988). While only the effect of the variability of wind on the variability on transport is of interest all other (wind independent) constants are assumed to be averaged out due to (later) normalization.

Representative values of wind speed and direction for 1 day measured at IJmuiden weather station are used to calculate DP's. Yearly Resultant Drift Potentials (RDP's) en the associated Resultant Drift Directions (RDD's) are calculated using vector summation of all daily DP's. Figure 6 shows the wind rose for IJmuiden wind station together with the derived annual RDP
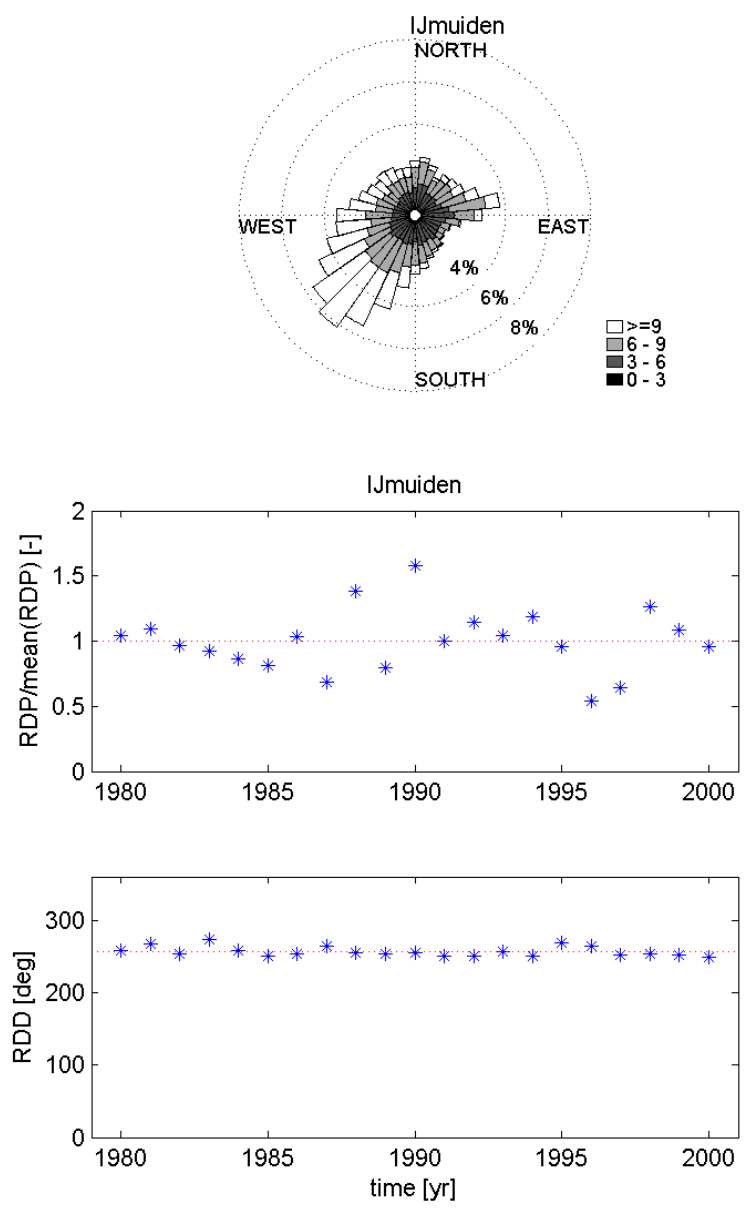

Figure 6. Wind conditions measured at IJmuiden weather station from the period 1980-2000.

(normalized with the mean) and RDD. It is shown that the annual RDP's vary around the mean with a factor 2 . Moreover the RDD seems to be very constant in time averaging around 256 degrees.

\section{CROSS-CORRELATIONS}

Using the data series derived above, cross correlations are used to show to what extend parameters are related.

\section{Dune Volume changes and RDP.}

Given that dune growth is partly governed by aeolian processes (Figure 1), it could be expected that dune volume changes correlate well with wind conditions. At this stage it is assumed that the wind conditions at IJmuiden are representative for the total Holland coast. The time series of dune volume changes at every profile location is correlated with the time series of normalized RDP's derived from the data measured at the IJmuiden station.

Testing cross correlations at every transect location on the $95 \%$ significance interval it is found that the number of transects where dune volume changes correlates positive and significant with wind speed is less than $3 \%$. Therefore we find no correlation between wind speed and dune volume changes. 
Note that while calculating RDP's, $u_{t 0}$ is assumed to be $5 \mathrm{~m} / \mathrm{s}$ based on results by Arens (1996). Other values ranging from 0-10 $\mathrm{m} / \mathrm{s}$ are also tested with no significant change in results.

\section{Dune Volume changes and Beach Slope.}

Hardisty and Whitehouse (1988) quantify (empirically) the influence of bed slope on aeolian sediment transport rates. Their results imply that where the bed slope increases from 0 to 2 degrees, aeolian transport rates decrease in the order of $30-40 \%$. Based on these findings, correlation between dune volume changes and beach slope are expected to some degree.

Figure 7 shows cross correlations at every transect location. A time lag is shown while a delay might be expected in the reaction of the dune volume changes on changes of beach slope. The percentage of transect locations where dune volume changes correlate significant with beach slope peak at a lag of zero on $11 \%$. This indicates that there is some correlation between both parameters and no time lag is present. The transect locations where significant correlations are found are evenly distributed over the entire Holland coast.

\section{DISCUSSION}

The lack of correlation between wind conditions and dune volume changes could be explained by effects due to transport limiting conditions (Davidson Arnott and Law, 1990). Variability of these transport limiting processes could overshadow variability induced by wind forcing (e.g. when strong winds are accompanied with rain, transport might be limited to the point where no transport occurs). Based on these results, process based predictive models where wind forcing is used as primary forcing and therefore a large wind driven variability of sediment transport rates and as a result dune volume changes, should be reconsidered or adapted before using them for coastal situations.

The found correlations between beach slope and dune volume changes could possibly represent the effect of transport limiting conditions. The transport limiting processes could be represented by the upslope effect described by Hardisty and Whitehouse (1988). Also sediment supply from the marine zone could be very relevant where sediment supply can both, limit (or stimulate) transport and cause milder beach slopes. Future research might shed some more light on this.

\section{CONCLUSION AND OUTLOOK}

\section{Conclusion}

After the analysis it is concluded that:

1. A large part of dune volumes along the Holland coast develop linearly in time.

2. Variability in time of dune volume changes do not correlate with wind conditions

3. Variability in time of dune volume changes do correlate with local beach slope.

\section{Outlook}

This research fits into the framework presented by de Groot et. al. (2012, This Issue).

The described procedure of correlating parameters extracted from the JARKUS dataset could lead to new insight on governing processes relevant to dune development and coastal development
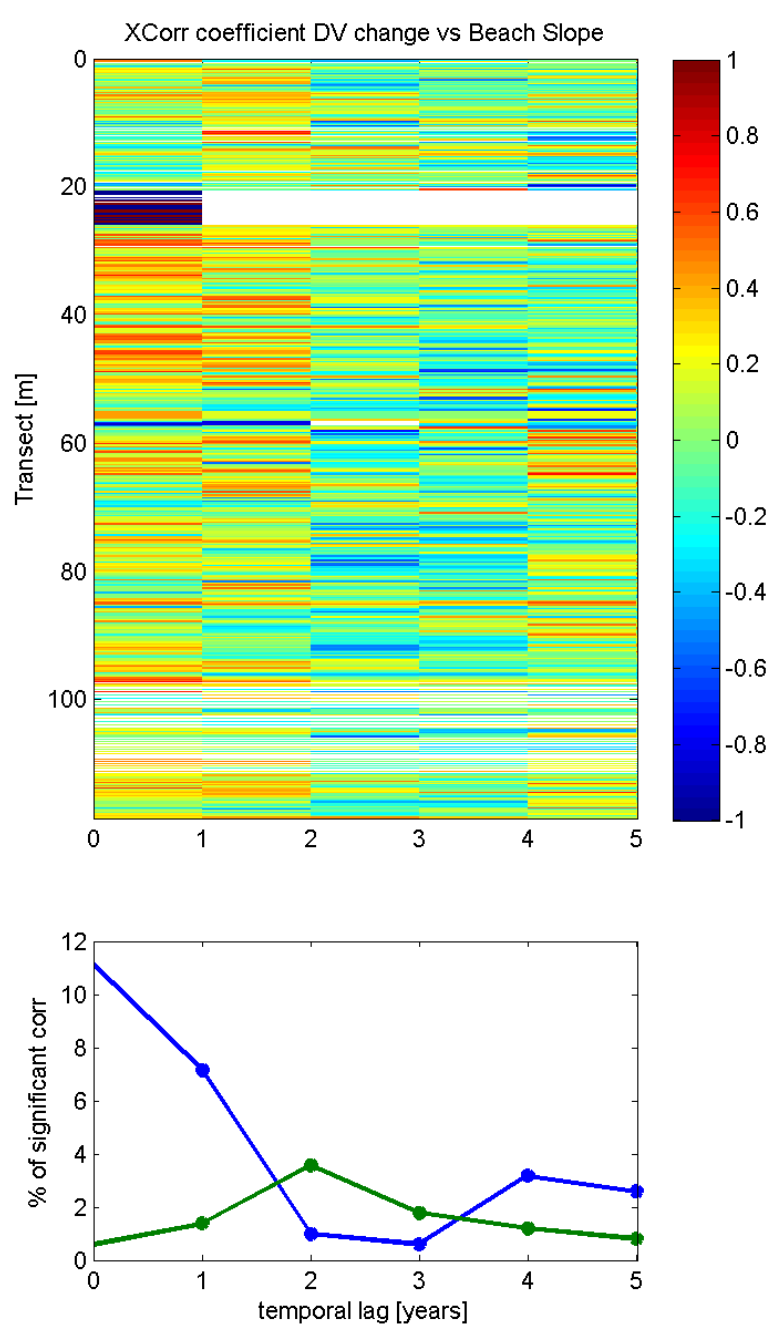

Figure 7. Top panel shows the cross correlation between dune volume change and beach slope at every transect location. Bottom panel shows the percentage of transect locations where a significant correlation (positive - blue line, negative - green line) is found.

in general. Based on the correlations, processes could be identified and quantified. According to the presented framework by de Groot et. al. (2012), the JARKUS data and the correlation procedures could further be exploited for the purpose of evaluating existing models for dune development as well as form a basis for new process formulations.

Setting aside a process based approach, the correlation and the data itself can be used as a basis for a data model. In a first effort, a Bayesian network model is set up based on the described data on dune volume changes and beach slope. Figure 8 shows such a network model. Using this model, a step of Bayesian interference provides a conditional prediction of the expected value (and its standard deviation) of dune volume change given beach slope at a given transect location. The Bayesian network model can easily be 
extended towards other domains such as specific nourishment situations, Wadden islands or data from other countries. Moreover additional parameters (such as MKL volumes, foreshore slopes, marine conditions) could also be added to fine-tune these data based predictions

\section{REFERENCES}

de Groot, A., de Vries, S., Keijsers, J., Riksen, M., Ye, Q., Poortinga, A., Arens, S. M., der Burgh, L. B.-V., Wijnberg, K., Schretlen, J. and van Thiel de Vries, J. (2012), Measuring and modeling coastal dune development in the Netherlands, NCKDays 2012, (This Issue).

Arens, S. M. (1996), Rates of aeolian transport on a beach in a temperate humid climate, Geomorphology, 17 (1-3), 3 - 18

Bochev-van der Burgh, L.M., Wijnberg, K.M. , Hulscher, S.J.M.H. (2011), Decadal-scale morphologic variability of managed coastal dunes, Coastal Engineering, 58 (9), 927 -936.

Davidson-Arnott, R. G. D., Law, M. N. (1990), Seasonal patterns and controls on sediment supply to coastal foredunes, long point, lake erie. In: Nordstrom, K. F., Psuty, N. P., Carter, R. W. G. (Eds.), Coastal Dunes: Form and Process. John Wiley \& Sons Ltd., pp. 177-200.

Fryberger, S. (1979), Dune forms and wind regime. A Study of Global Sand Seas, USGS Professional Paper 1052, 137-16

Hardisty, J., Whitehouse, R. J. S., Apr. (1988), Evidence for a new sand transport process from experiments on saharan dunes. Nature 332 (6164), 532-534.

\section{ACKNOWLEDGEMENTS}

Sierd de Vries was funded by the innovation program Building with Nature. The Building with Nature program is funded from several sources, including the Subsidieregeling Innovatieketen Water (SIW, Staatscourant nrs 953 and 17009) sponsored by the Dutch Ministry of Transport, Public Works and Water Management and partner contributions of the participants to the Foundation EcoShape. The program receives co-funding from the European Fund for Regional Development EFRO and the Municipality of Dordrecht.

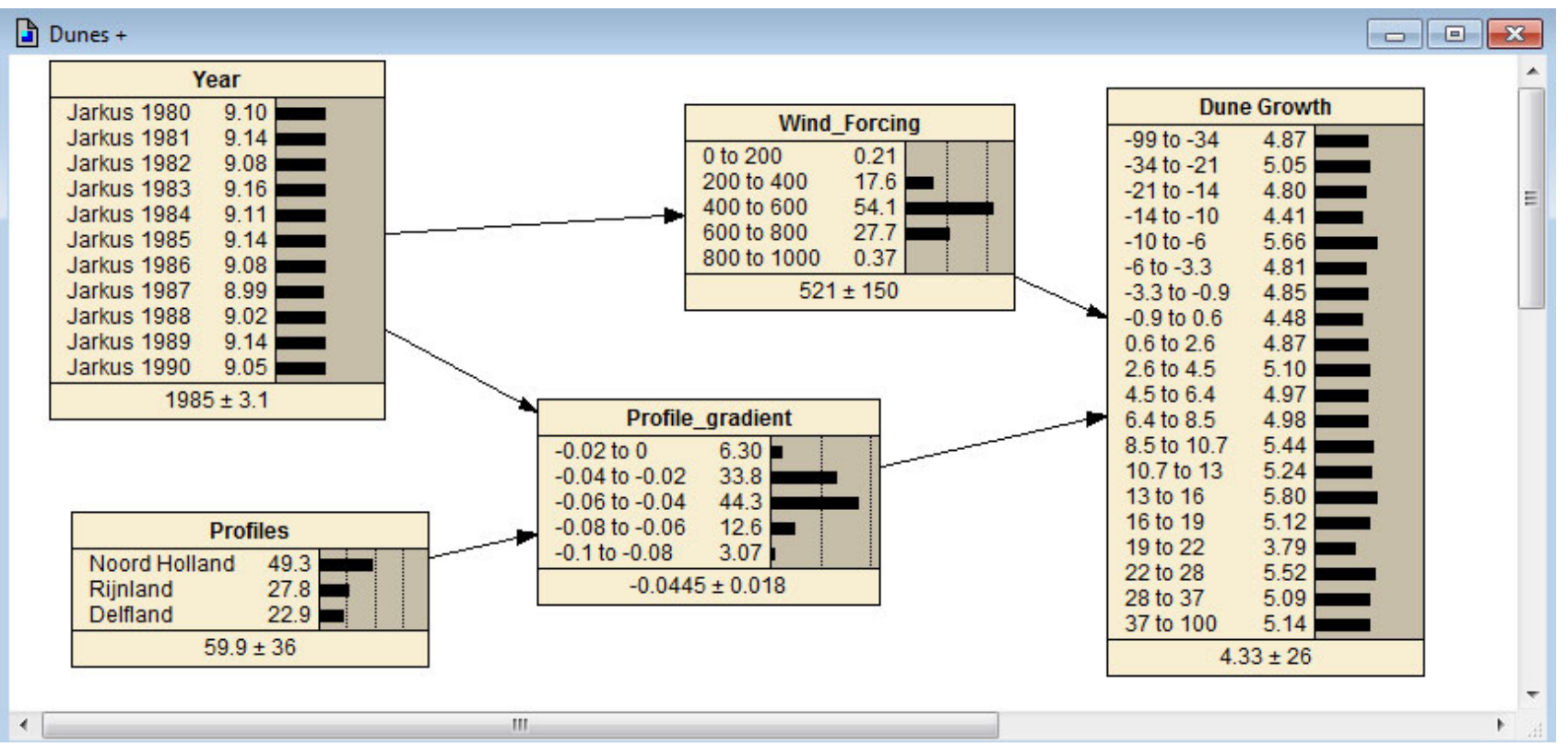

Figure 8. Initial Bayesian network model. 